\title{
Radiosurgery for temporal lobe arteriovenous malformations: effect of temporal location on seizure outcomes
}

\author{
Dale Ding, MD, ${ }^{1}$ Mark Quigg, MD, MSc, ${ }^{2}$ Robert M. Starke, MD, MSc, ${ }^{1}$ Zhiyuan Xu, MD, ${ }^{1}$ \\ Chun-Po Yen, MD, ${ }^{1}$ Colin J. Przybylowski, BS, ${ }^{1}$ Blair K. Dodson, BSN, ${ }^{1}$ and \\ Jason P. Sheehan, MD, PhD'1
}

Departments of ${ }^{1}$ Neurological Surgery and ${ }^{2}$ Neurology, University of Virginia, Charlottesville, Virginia

\begin{abstract}
OBJECT The temporal lobe is particularly susceptible to epileptogenesis. However, the routine use of anticonvulsant therapy is not implemented in temporal lobe AVM patients without seizures at presentation. The goals of this case-control study were to determine the radiosurgical outcomes for temporal lobe AVMs and to define the effect of temporal lobe location on postradiosurgery AVM seizure outcomes.
\end{abstract}

METHODS From a database of approximately 1400 patients, the authors generated a case cohort from patients with temporal lobe AVMs with at least 2 years follow-up or obliteration. A control cohort with similar baseline AVM characteristics was generated, blinded to outcome, from patients with non-temporal, cortical AVMs. They evaluated the rates and predictors of seizure freedom or decreased seizure frequency in patients with seizures or de novo seizures in those without seizures.

RESULTS A total of 175 temporal lobe AVMs were identified based on the inclusion criteria. Seizure was the presenting symptom in $38 \%$ of patients. The median AVM volume was $3.3 \mathrm{~cm}^{3}$, and the Spetzler-Martin grade was III or higher in $39 \%$ of cases. The median radiosurgical prescription dose was $22 \mathrm{~Gy}$. At a median clinical follow-up of 73 months, the rates of seizure control and de novo seizures were $62 \%$ and $2 \%$, respectively. Prior embolization $(p=0.023)$ and lower radiosurgical dose $(p=0.027)$ were significant predictors of seizure control. Neither temporal lobe location $(p=0.187)$ nor obliteration ( $p=0.522$ ) affected seizure outcomes. The cumulative obliteration rate was $63 \%$, which was significantly higher in patients without seizures at presentation $(p=0.046)$. The rates of symptomatic and permanent radiationinduced changes were $3 \%$ and $1 \%$, respectively. The annual risk of postradiosurgery hemorrhage was $1.3 \%$.

CONCLUSIONS Radiosurgery is an effective treatment for temporal lobe AVMs. Furthermore, radiosurgery is protective against seizure progression in patients with temporal lobe AVM-associated seizures. Temporal lobe location does not affect radiosurgery-induced seizure control. The low risk of new-onset seizures in patients with temporal or extratemporal AVMs does not seem to warrant prophylactic use of anticonvulsants.

http://thejns.org/doi/abs/10.3171/2014.10.JNS141807

KEY WORDS epilepsy; Gamma Knife; intracranial arteriovenous malformation; stereotactic radiosurgery; seizures; temporal lobe; vascular malformations; vascular disorders

$\mathrm{T}$ Reatment of temporal lobe arteriovenous malformations (AVMs) carries burdens beyond the primary consideration of prevention of hemorrhage. Prior studies of AVM-associated epilepsy have shown that higher rates of epilepsy are associated with temporal lobe involvement. ${ }^{20,23,24,48}$ Interventional therapy has the potential to control AVM-associated epilepsy. ${ }^{2,23}$ Since post- treatment epilepsy status has a strong influence on quality of life and functional outcomes, treatment-induced seizure control is an important consideration. ${ }^{25}$

Thus, the success of an intervention is dictated by more than obliteration of the AVM nidus. Radiosurgery is a minimally invasive treatment alternative to microsurgery for AVMs and induces gradual obliteration of the nidus over

ABBREVIATIONS AED = antiepileptic drug; AVM = arteriovenous malformation; MTLE = mesial temporal lobe epilepsy; RBAS = radiosurgery-based AVM score; RIC = radiation-induced change; VRAS = Virginia Radiosurgery AVM Scale.

SUBMITTED August 6, 2014. ACCEPTED October 20, 2014.

INCLUDE WHEN CITING Published online April 17, 2015; DOI: 10.3171/2014.10.JNS141807.

DISCLOSURE The authors report no conflict of interest concerning the materials or methods used in this study or the findings specified in this paper. 
a typical period of 2 to 3 years. ${ }^{37,47}$ While AVM radiosurgery outcomes have been previously reported by our institution and other neurosurgical centers, the relationship between temporal lobe location and AVM radiosurgery outcomes, specifically with regard to seizure control, has not been previously defined..$^{9-11,27,33}$ Furthermore, despite the particular susceptibility of patients harboring temporal lobe lesions to seizures, antiepileptic drug (AED) therapy is not routinely administered to patients with temporal lobe AVMs who do not have seizures at presentation. ${ }^{14}$ Therefore, the goals of the present study are 1) to evaluate the radiosurgery outcomes, with respect to seizure control, obliteration, and complications, for temporal lobe AVMs and 2) to determine the effect of temporal lobe location on seizure control following AVM radiosurgery.

\section{Methods \\ Patient Selection}

This is a single-center, retrospective, case-control cohort study evaluated from a prospectively collected database, approved by the University of Virginia institutional review board, of over 1400 AVM patients treated with Gamma Knife radiosurgery from 1989 to 2012. The inclusion criteria for the case cohort were 1) temporal lobe AVM location, 2) data regarding presence or absence of seizures at presentation, 3) data regarding posttreatment seizure outcomes available, 4) complete AVM obliteration following radiosurgery, and 5) minimum posttreatment follow-up duration of 2 years for AVMs without obliteration. Patients who had more than 1 radiosurgery treatment were not excluded, but the duration of follow-up was calculated from the last procedure.

\section{Radiosurgery Procedure}

The Gamma Knife (Elekta) radiosurgery procedure was performed in a standard fashion as previously described ${ }^{47}$ Prior to 1991 , MRI was not routinely used in addition to angiography for treatment planning. After 1991, a combination of MRI and angiography were routinely used to optimize the spatial accuracy of radiosurgical planning. From 1989 until June 1994, the Kula software was used for dose planning. From July 1994 onward, dose planning was performed with the GammaPlan software (Elekta).

\section{Data and Variables}

The following variables were obtained from the database and directed chart review: patient demographic characteristics (sex, age, and presenting symptom), baseline AVM characteristics (prior hemorrhage, prior embolization, prior resection, maximum diameter, volume, eloquent location, location and number of draining veins, and presence of associated aneurysms), and radiosurgery characteristics (prescription dose, maximum dose, isodose line, and number of isocenters). The Spetzler-Martin grade, modified radiosurgery-based AVM score (RBAS), and Virginia Radiosurgery AVM Scale (VRAS) were determined for each nidus. ${ }^{45,46,49}$

To determine the effect of temporal lobe location on AVM-associated seizure outcomes following radiosurgery, a control cohort of patients with non-temporal corti- cal AVMs was generated from the same institutional database. The inclusion criteria for the control cohort were the same as those for the case cohort with the exception of location (i.e., frontal, parietal, or occipital lobe location for the control cohort vs temporal lobe location for the case cohort). To prevent statistical bias due to differences in baseline AVM characteristics and treatment parameters, the control cohort was selected so that the frequencies of preradiosurgery hemorrhage, preradiosurgery embolization and resection, eloquent location, presence of deep venous drainage, number of draining veins, and presence of associated aneurysms and the means of the nidus volume and prescription dose did not differ significantly between the temporal lobe AVM and non-temporal, cortical AVM cohorts. The generation of the control cohort was performed blinded to outcome and was conducted separately for AVM patients presenting with seizures and AVM patients not presenting with seizures.

\section{Radiological and Clinical Follow-Up}

Information regarding seizure status was extracted from the chart and categorized as seizure free (with seizure freedom being patient-defined absence of seizures) or as not seizure free (patient-defined improved, unchanged, or worsened seizure rates). Seizure control was defined, in patients with seizures at presentation, as seizure freedom or decreased seizure frequency regardless of AED therapy. Seizure worsening was defined as increased frequency or intensity of seizures regardless of AED therapy. For the purposes of data analysis, postradiosurgery seizure outcomes were dichotomized into those patients with seizure control and those patients without seizure control (i.e., unchanged seizure status or worsening). De novo seizures were defined, in patients without seizure presentation, as new-onset seizures occurring after the radiosurgery procedure. Clinical follow-up was obtained from a combination of clinic appointments and hospital admissions to the University of Virginia and correspondence with patients' local referring physicians and outside hospitals.

Patients were monitored with serial MRI studies every 6 months after radiosurgery for the first 2 years, followed by annual MRIs after the first 2 years. Neuroimaging in addition to routine follow-up imaging was obtained in patients with neurological decline. All follow-up imaging was reviewed by a neurosurgeon and a neuroradiologist at the University of Virginia, regardless of where it was obtained. AVM obliteration was defined on MRI by the absence of flow voids or on angiography by the lack of aberrant arteriovenous shunting. Angiography was typically reserved for AVMs that were determined to be completely obliterated on MRI. Hemorrhage was defined on CT or MRI with or without correlation to new or worsening neurological deficits. Radiation-induced changes (RIC) were defined on follow-up MRI by perinidal T2-weighted hyperintensities. RICs were classified as symptomatic if they correlated with clinical symptoms, most commonly headache, focal neurological deficit, or seizure.

\section{Statistical Analysis}

Statistical analysis was performed with the IBM SPSS 
20 software program. Data are presented as mean and range for continuous variables and as frequency for categorical variables. For patients with seizures at presentation, the primary outcome variable was seizure control. For patients without seizures at presentation, the primary outcome variable was de novo seizures. The baseline AVM characteristics, radiosurgical treatment parameters, and postradiosurgery outcomes were compared between the temporal lobe AVM and non-temporal, cortical AVM cohorts using the unpaired Student t-test for continuous variables or Pearson chi-square test for categorical variables.

Since the case and control cohorts had statistically similar AVM characteristics and radiosurgery treatment parameters, the 2 cohorts were merged for the univariate logistic regression analysis for predictors of seizure control. Covariates included in the logistic regression analysis were temporal lobe location, sex, age, prior AVM hemorrhage, prior embolization, prior resection, AVM volume, AVM location (non-eloquent vs eloquent), location of draining veins (exclusively superficial vs deep or both), number of draining veins (single vs multiple), prescription dose, Spetzler-Martin grade, RBAS, VRAS score, obliteration, radiological presence of RIC, postradiosurgery cyst formation, and postradiosurgery hemorrhage. Interaction and confounding was assessed through stratification and relevant expansion covariates. Factors predictive in univariate analysis $(\mathrm{p}<0.20)$ were entered into a multivariate logistic regression analysis. A p value less than 0.05 was considered statistically significant. All statistical tests were 2 -sided. For patients without seizures at presentation, the incidence of de novo seizures was too low to justify performing a logistic regression analysis.

Nidus obliteration was reported as a cumulative percentage that combined obliteration confirmed by angiography and obliteration determined by MRI alone. KaplanMeier analysis was performed to determine the actuarial obliteration rates over time. The actuarial obliteration rates were calculated separately for patients with and without presenting seizures and were statistically compared with the log-rank test. The annual postradiosurgery hemorrhage risk was calculated by dividing the total number of latencyperiod hemorrhages by the total number of risk years. The number of risk years for each patient was defined as the time interval between radiosurgery and obliteration or last radiological follow-up for nonobliterated AVMs.

\section{Results \\ Comparison of Baseline Characteristics of Case and Control Cohorts}

A total of 175 patients with temporal lobe AVMs met the inclusion criteria for analysis (Table 1). For the analysis of seizure control, the case cohort comprised 66 patients with temporal lobe AVMs who presented with seizures, and the control cohort comprised 122 patients with non-temporal, cortical AVMs who presented with seizures (Table 2). For the analysis of de novo seizures, the case cohort comprised 109 patients with temporal lobe AVMs who did not present with seizures, and the control cohort comprised 252 patients with non-temporal, cortical AVMs who did not present with seizures (Table 3). There were no statistically significant differences in the AVM and treatment characteristics between the case and control cohorts for patients with or without seizure presentation.

\section{Effect of Temporal Lobe Location on Postradiosurgery Seizure Control}

Of the 66 temporal lobe AVM patients who presented with seizures, 5 (7.6\%) had worsening of their seizures after radiosurgery. At last follow-up, seizure control was achieved in 41 patients $(62.1 \%)$-seizure freedom in 12 patients (18.2\%) and decreased seizure frequency in 29 patients $(43.9 \%)$. The remaining 20 patients had unchanged seizure outcomes following radiosurgery (30.3\%). The rates of seizure freedom and control for patients with obliterated temporal lobe AVMs were $22.2 \%$ (8/36 patients) and $66.7 \%$ (24/36 patients), respectively. The rates of seizure freedom and control for patients with patent temporal lobe AVMs were $13.3 \%$ (4/30 patients) and 56.7\% (17/30 patients), respectively (Fig. 1). Obliteration of the nidus did not significantly alter the rate of seizure freedom or control for patients with seizure presentation $(\mathrm{p}=0.103$ and $\mathrm{p}$ $=0.404$, respectively).

Of the 122 non-temporal, cortical AVM patients who presented with seizures, seizure control was achieved in 63 patients (51.6\%), including seizure freedom in 18 patients $(14.8 \%)$. The rates of seizure control and seizure freedom for patients with obliterated nidi were 52.9\% (36/68 patients) and $16.2 \%$ (11/68 patients). Compared with patients with angioarchitecturally similar non-temporal cortical AVMs (Fig. 2A), patients with temporal lobe AVMs presenting with seizures did not have significantly different rates of seizure control $(\mathrm{p}=0.168)$ or seizure freedom $(\mathrm{p}$ $=0.540$ ). When only patients with completely obliterated nidi were considered, the differences between the 2 cohorts were also nonsignificant with respect to seizure control $(p=0.178)$ and seizure freedom $(p=0.448)$.

Based on the univariate logistic regression analysis, preradiosurgery embolization $(\mathrm{p}=0.023)$ and lower prescription dose $(\mathrm{p}=0.027)$ were significant predictors of postradiosurgery seizure control (Table 4 ). In addition to these 2 covariates, temporal lobe location $(\mathrm{p}=0.187)$, male sex ( $\mathrm{p}$ $=0.120)$, preradiosurgery hemorrhage $(\mathrm{p}=0.064)$, higher volume $(p=0.056)$, non-eloquent location $(p=0.087)$, and higher RBAS ( $p=0.091)$ were selected for further analysis in the multivariate model. Multivariate logistic regression analysis did not identify any factors that were significantly associated with seizure control. Therefore, temporal lobe location was not significantly associated with seizure control. Additionally, obliteration was not associated with seizure control in the logistic regression analysis $(p=0.522)$.

\section{Effect of Temporal Lobe Location on De Novo Seizures After Radiosurgery}

Of the 109 temporal lobe AVM patients without seizures at presentation, 2 had de novo seizures after radiosurgery (1.8\%) including $1.3 \%$ in obliterated (1/75 patients) and $2.9 \%$ in patent (1/34 patients) AVMs. AVM obliteration did not significantly alter the incidence of de novo seizures for patients without seizure presentation $(\mathrm{p}=0.562)$. Of the 252 non-temporal, cortical AVM patients without seizure 
TABLE 1. Temporal lobe AVM cohort patient demographic characteristics, nidus characteristics, and treatment parameters

\begin{tabular}{|c|c|}
\hline Characteristic & Value \\
\hline \multicolumn{2}{|l|}{ Sex } \\
\hline Male & $85(48.6 \%)$ \\
\hline Female & $90(51.4 \%)$ \\
\hline \multicolumn{2}{|l|}{ Age (yrs) } \\
\hline Mean & 36.6 \\
\hline Median & 35.3 \\
\hline Range & $8.0-74.6$ \\
\hline Pediatric patients (age <18 yrs) & $23(13.1 \%)$ \\
\hline Preradiosurgery hemorrhage & $85(48.6 \%)$ \\
\hline Preradiosurgery embolization & $44(25.1 \%)$ \\
\hline Preradiosurgery resection & $26(14.9 \%)$ \\
\hline \multicolumn{2}{|l|}{ Presenting symptom } \\
\hline Hemorrhage & $78(44.6 \%)$ \\
\hline Seizure & $66(37.7 \%)$ \\
\hline Headache & $14(8.0 \%)$ \\
\hline Focal neurological deficit & $7(4.0 \%)$ \\
\hline Asymptomatic & $5(2.9 \%)$ \\
\hline \multicolumn{2}{|l|}{ Max diameter (cm) } \\
\hline Mean & 2.4 \\
\hline Median & 2.4 \\
\hline Range & $0.9-5.5$ \\
\hline \multicolumn{2}{|l|}{ Volume $\left(\mathrm{cm}^{3}\right)$} \\
\hline Mean & 4.1 \\
\hline Median & 3.3 \\
\hline Range & $0.1-33.0$ \\
\hline \multicolumn{2}{|l|}{ Eloquent location } \\
\hline Non-eloquent & $82(46.9 \%)$ \\
\hline Eloquent & $93(53.1 \%)$ \\
\hline \multicolumn{2}{|l|}{ Venous drainage pattern } \\
\hline Superficial & $92(52.6 \%)$ \\
\hline Deep & $83(47.4 \%)$ \\
\hline \multicolumn{2}{|l|}{ No. of draining veins } \\
\hline Single & $91(52.0 \%)$ \\
\hline Multiple & $84(48.0 \%)$ \\
\hline \multicolumn{2}{|l|}{ Associated aneurysms } \\
\hline Intranidal & $5(2.8 \%)$ \\
\hline Perinidal & $4(2.3 \%)$ \\
\hline \multicolumn{2}{|l|}{ Spetzler-Martin grade } \\
\hline 1 & $36(20.6 \%)$ \\
\hline II & $68(38.9 \%)$ \\
\hline III & $55(31.4 \%)$ \\
\hline IV & $16(9.1 \%)$ \\
\hline V & 0 \\
\hline \multicolumn{2}{|l|}{ RBAS } \\
\hline Mean & 1.15 \\
\hline Median & 1.10 \\
\hline Range & $0.21-3.90$ \\
\hline$<1.00$ & $67(38.3 \%)$ \\
\hline
\end{tabular}

TABLE 1. Temporal lobe AVM cohort patient demographic characteristics, nidus characteristics, and treatment parameters (continued)

\begin{tabular}{|c|c|}
\hline Characteristic & Value \\
\hline \multicolumn{2}{|l|}{ RBAS (continued) } \\
\hline $1.00-1.50$ & $73(41.7 \%)$ \\
\hline $1.51-2.00$ & $39(17.1 \%)$ \\
\hline$>2.00$ & $5(2.9 \%)$ \\
\hline \multicolumn{2}{|l|}{ VRAS score } \\
\hline $0-1$ & $49(28.0 \%)$ \\
\hline 2 & $57(32.6 \%)$ \\
\hline 3 & $55(31.4 \%)$ \\
\hline 4 & $14(8.0 \%)$ \\
\hline \multicolumn{2}{|l|}{ Prescription dose (Gy) } \\
\hline Mean & 21.1 \\
\hline Median & 22 \\
\hline Range & $9-30$ \\
\hline \multicolumn{2}{|l|}{ Max dose (Gy) } \\
\hline Mean & 39.4 \\
\hline Median & 40 \\
\hline Range & $24-60$ \\
\hline \multicolumn{2}{|l|}{ Isodose line (\%) } \\
\hline Mean & 54.4 \\
\hline Median & 50 \\
\hline Range & $30-90$ \\
\hline \multicolumn{2}{|l|}{ No. of isocenters } \\
\hline Mean & 2.9 \\
\hline Median & 2 \\
\hline Range & $1-22$ \\
\hline \multicolumn{2}{|c|}{ Radiologic follow-up (mos) } \\
\hline Mean & 72.7 \\
\hline Median & 59.0 \\
\hline Range & $6.2-230.4$ \\
\hline \multicolumn{2}{|l|}{ Clinical follow-up (mos) } \\
\hline Mean & 84.9 \\
\hline Median & 73.3 \\
\hline Range & $6.2-230.4$ \\
\hline
\end{tabular}

presentation, five had de novo seizures after radiosurgery (2.0\%), including $2.5 \%$ in obliterated (5/198 patients) and $0 \%$ in patent $(0 / 54$ patients) AVMs. The difference in the incidence of de novo seizures was not significantly different between the case and control cohorts when including all AVMs $(p=0.925)$ and when including only obliterated AVMs $(\mathrm{p}=0.549)$ in patients without seizure presentation (Fig. 2B). Therefore, temporal lobe location was not associated with postradiosurgery de novo seizures.

\section{Radiological and Clinical Outcomes for Temporal Lobe AVM Patients After Radiosurgery}

Complete AVM obliteration was defined by MRI in 32 patients (18.3\%) and confirmed by angiography in 79 patients $(45.1 \%)$ for a cumulative obliteration rate of $63.4 \%$ 
TABLE 2. Comparison of temporal lobe and non-temporal cortical AVM cohorts for patients with seizure presentation

\begin{tabular}{|c|c|c|c|}
\hline Factor & $\begin{array}{l}\text { Patients w/ Temporal Lobe AVMs } \\
\text { Presenting w/ Seizure }(n=66)\end{array}$ & $\begin{array}{l}\text { Patients w/ Non-Temporal, Cortical } \\
\text { AVMs Presenting w/ Seizure }(n=122)\end{array}$ & $\mathrm{p}$ Value \\
\hline Preradiosurgery hemorrhage & $5(7.6 \%)$ & $7(5.7 \%)$ & 0.623 \\
\hline Preradiosurgery embolization & $18(27.3 \%)$ & $46(37.7 \%)$ & 0.150 \\
\hline Preradiosurgery resection & $3(4.5 \%)$ & $7(5.7 \%)$ & 0.728 \\
\hline Volume $\left(\mathrm{cm}^{3}\right)$ & & & 0.863 \\
\hline Mean & 5.1 & 5.2 & \\
\hline $95 \% \mathrm{Cl}$ & $4.0-6.1$ & $4.5-5.8$ & \\
\hline Eloquent location & $36(54.5 \%)$ & $76(62.3 \%)$ & 0.301 \\
\hline Deep venous drainage & $27(40.9 \%)$ & $39(32.0 \%)$ & 0.220 \\
\hline Single draining vein & $25(37.9 \%)$ & $51(41.8 \%)$ & 0.601 \\
\hline Associated aneurysms & $4(6.1 \%)$ & $6(4.9 \%)$ & 0.739 \\
\hline Spetzler-Martin grade & & & 0.611 \\
\hline Mean & 2.3 & 2.4 & \\
\hline $95 \% \mathrm{Cl}$ & $2.1-2.6$ & $2.3-2.6$ & \\
\hline RBAS & & & 0.330 \\
\hline Mean & 1.27 & 1.20 & \\
\hline $95 \% \mathrm{Cl}$ & $1.15-1.39$ & $1.12-1.28$ & \\
\hline VRAS score & & & 0.574 \\
\hline Mean & 2.0 & 2.1 & \\
\hline $95 \% \mathrm{Cl}$ & $1.8-2.3$ & $1.9-2.3$ & \\
\hline Prescription dose (Gy) & & & 0.790 \\
\hline Mean & 20.1 & 20.0 & \\
\hline $95 \% \mathrm{Cl}$ & $19.3-20.9$ & $19.3-20.6$ & \\
\hline
\end{tabular}

(111/175 patients). The actuarial obliteration rates for all temporal lobe AVMs at 3, 5, and 10 years were $29 \%, 47 \%$, and $68 \%$, respectively (Fig. 3). The median time to obliteration was 66 months. For patients with seizure presentation, the actuarial obliteration rates at 3, 5, and 10 years were $20 \%, 39 \%$, and $62 \%$, respectively, with a median time to obliteration of 73 months. For patients without seizure presentation, the actuarial obliteration rates were $33 \%, 52 \%$, and $72 \%$, respectively, with a median time to obliteration of 54 months. The obliteration rate was significantly higher in patients without seizure presentation ( $p=0.046$, log-rank test; Fig. 4).

One AVM hemorrhage occurred during the latency period following radiosurgery in each of 12 patients over a total of 900 risk years, yielding a postradiosurgery hemorrhage risk of $1.3 \%$ per year. RIC was evident in a total of 54 patients $(30.9 \%)$, of which 5 patients were symptomatic $(2.9 \%)$. RIC-associated symptoms included focal neurological deficits in four patients $(2.3 \%)$ and new-onset seizures in one patient $(0.6 \%)$. Permanent deficits from RIC were present in 2 patients $(1.1 \%)$. The median time to RIC onset was 11.9 months after radiosurgery, and the median duration of RIC was 13.3 months. Postradiosurgery cyst formation was observed in 7 patients (4.1\%).

Repeat radiosurgery was performed in 20 patients $(11.4 \%)$ with incompletely obliterated AVMs at three years follow-up. The median AVM volume at the time of repeat treatment was $1.2 \mathrm{~cm}^{3}$ (range $0.2-3.5 \mathrm{~cm}^{3}$ ). The median repeat radiosurgery parameters were prescription dose 21
Gy (range 16-27 Gy), maximum dose 33 Gy (range 22-50 Gy), isodose line 53\% (range 50\%-90\%), and number of isocenters 2 (range 1-20).

\section{Discussion}

The temporal lobe coordinates multiple cortical functions and may also be particularly susceptible to epileptic injury.7,14,17,50 Temporal lobe AVMs are difficult to safely resect, especially those in the dominant hemisphere, where the vascular supply to language function may also be intimately involved with the nidus. ${ }^{15}$ Indeed, $53 \%$ of the temporal lobe AVMs in our series were located in eloquent cortex. Language mapping may assist in intraoperative management of eloquent AVMs but may force the surgeon to decide between complete resection and functional preservation. ${ }^{18}$ In contrast to resection, radiosurgery offers a method of progressive AVM occlusion over time via intimal proliferation, hyaline transformation, and vascular thrombosis. ${ }^{5,43}$ Our prior studies have suggested that AVM radiosurgical outcomes may not be as strongly influenced by eloquent location as surgical outcomes. ${ }^{13,41}$ Therefore, we propose that radiosurgery for temporal lobe AVMs is a reasonable alternative to resection.

\section{Relationship Between Temporal Lobe AVM Location and Seizures}

AVM location in the temporal lobe has been linked to seizures at presentation, although this relationship is 
TABLE 3. Comparison of temporal lobe and non-temporal cortical AVM cohorts for patients without seizure presentation

\begin{tabular}{|c|c|c|c|}
\hline Factor & $\begin{array}{c}\text { Temporal Lobe AVMs w/o } \\
\text { Presenting Seizure }(n=109)\end{array}$ & $\begin{array}{l}\text { Non-Temporal, Cortical AVMs w/o } \\
\text { Presenting Seizures }(n=252)\end{array}$ & p Value \\
\hline Preradiosurgery hemorrhage & $80(73.4 \%)$ & $176(69.8 \%)$ & 0.495 \\
\hline Preradiosurgery embolization & $26(23.9 \%)$ & $65(25.8 \%)$ & 0.697 \\
\hline Preradiosurgery resection & $23(21.1 \%)$ & $40(15.9 \%)$ & 0.230 \\
\hline Volume $\left(\mathrm{cm}^{3}\right)$ & & & 0.786 \\
\hline Mean & 3.6 & 3.5 & \\
\hline $95 \% \mathrm{Cl}$ & $2.9-4.3$ & $3.1-3.8$ & \\
\hline Eloquent location & $57(52.3 \%)$ & $146(57.9 \%)$ & 0.321 \\
\hline Deep venous drainage & $56(51.4 \%)$ & $125(49.6 \%)$ & 0.757 \\
\hline Single draining vein & $66(60.6 \%)$ & $150(59.5 \%)$ & 0.855 \\
\hline Associated aneurysms & $5(4.6 \%)$ & $14(5.6 \%)$ & 0.705 \\
\hline Spetzler-Martin grade & & & 0.467 \\
\hline Mean & 2.3 & 2.3 & \\
\hline $95 \% \mathrm{Cl}$ & $2.1-2.4$ & $2.2-2.4$ & \\
\hline RBAS & & & 0.335 \\
\hline Mean & 1.07 & 1.02 & \\
\hline $95 \% \mathrm{Cl}$ & $0.98-1.17$ & $0.97-1.07$ & \\
\hline VRAS score & & & 0.740 \\
\hline Mean & 2.2 & 2.3 & \\
\hline $95 \% \mathrm{Cl}$ & $2.0-2.4$ & $2.1-2.4$ & \\
\hline Prescription dose (Gy) & & & 0.681 \\
\hline Mean & 21.6 & 21.8 & \\
\hline $95 \% \mathrm{Cl}$ & $21.0-22.2$ & $21.4-22.2$ & \\
\hline
\end{tabular}

inconsistently reported across AVM series. In a prospective observational study of 101 AVM patients by Galletti et al., multivariate logistic regression analysis determined temporal lobe location to have the strongest correlation with seizures (OR 3.48, 95\% CI 1.77-6.85). ${ }^{20}$ Turjman et al. evaluated the angioarchitectural features of 100 AVMs associated with epilepsy and found temporal and parietal cortical locations and vascular supply by the external carotid artery to be significant predictors of epilepsy. ${ }^{48} \mathrm{An}$ other series of 155 cases reported by Garcin et al. showed frontal, rather than temporal, lobe location to be independently associated with seizures. ${ }^{21}$

Fierstra et al. proposed that AVM-associated seizures may be associated with impaired cerebrovascular reserve secondary to venous congestion based on a study of 20 AVM patients using MRI-based quantitative cerebrovascular reactivity mapping and angiography. ${ }^{16}$ AVMs may also alter the physiology and excitability of perinidal cortical neurons, thus predisposing patients with superficial nidi to the development of seizures. ${ }^{28}$ Furthermore, Yeh et al. suggested that the mesial temporal cortex may be susceptible to secondary epileptogenesis in patients with non-temporal AVMs, although this was only described in 2 individuals. ${ }^{53}$ Due to the scarcity of convincing evidence, none of the aforementioned mechanisms has been widely accepted. Thus, the etiology of AVM-associated epilepsy remains largely unknown.

\section{Seizure Outcomes Following Microsurgical Resection of Temporal Lobe AVMs}

In the present study, we found that the majority of patients with preradiosurgery seizures from temporal lobe AVMs reported remission or improvement after treatment. A comparison of the efficacies of radiosurgery to microsurgery for the amelioration of AVM-associated epilepsy is difficult due to inconsistent reporting in prior studies. In major published surgical series of temporal lobe AVMs, seizures were the presenting symptom in $15 \%-46 \%$ of patients (Table 5), 3,19,31,32,35,51 In congruence with the majority of studies in the AVM resection literature, the postoperative obliteration rates were excellent, in excess of $90 \%$. For patients who presented with seizures, the rate of postoperative seizure control was $50 \%-100 \%$. However, the documentation of seizure outcomes was inconsistent and heterogeneous, with only $50 \%$ of the microsurgical series reporting postoperative seizure outcomes.

\section{Effect of Radiosurgery on Seizures Outcomes for Patients With Temporal Lobe AVMs}

In our series of 175 patients with temporal lobe AVMs, seizures were the second most frequent presenting symptom $(38 \%)$. The obliteration rate was $63 \%$, which is consistent with our previously published series. ${ }^{8,12}$ Patients without seizure presentation were significantly more likely to achieve AVM obliteration than patients without seizure 


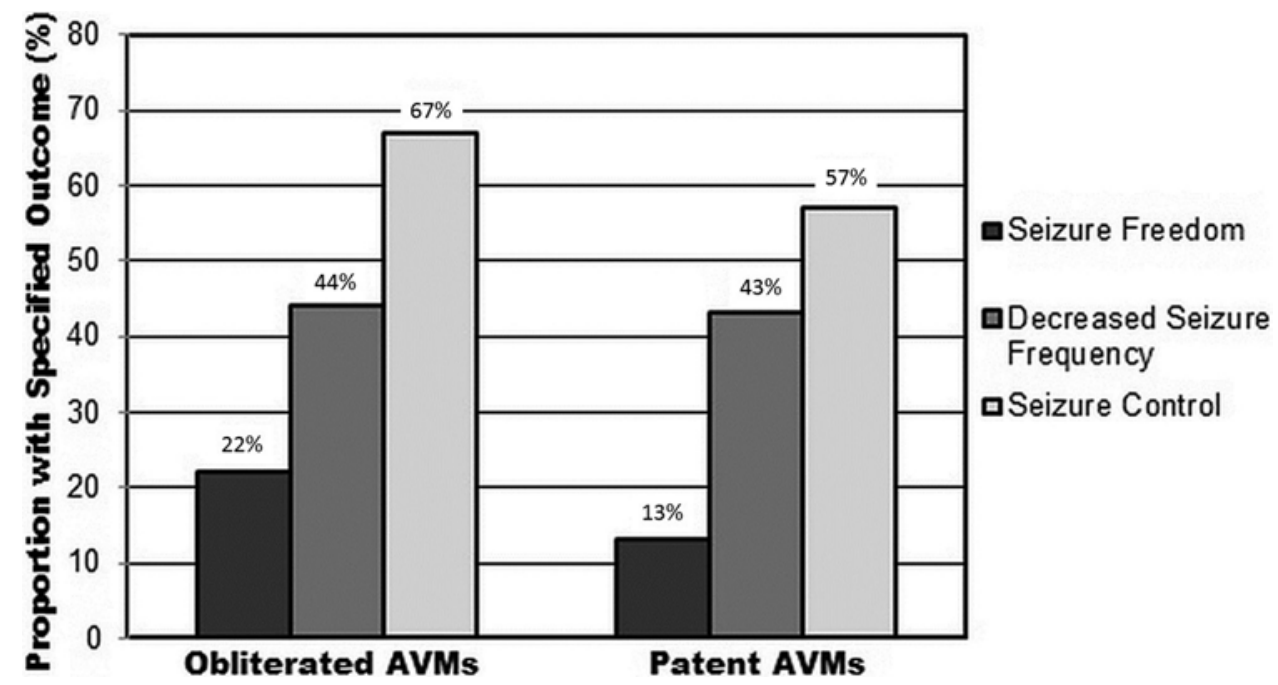

FIG. 1. Bar plots of the rates of seizure freedom, decreased seizure frequency, and seizure control for obliterated and patent temporal lobe AVMs in patients with seizures at presentation. Seizure control was defined as seizure freedom or decreased seizure frequency. There was no statistically significant difference between the obliterated and patent temporal lobe AVMs with respect to rates of seizure freedom $(p=0.103)$ or seizure control $(p=0.404)$.

presentation $(\mathrm{p}=0.046)$. The rates of seizure control $(62 \%)$ and de novo seizures (2\%) in the current series would compare quite favorably to the limited reports in the microsurgical literature for temporal AVMs. Nevertheless, the rate of seizure freedom was relatively low (18\%). Although the rate of seizure control was somewhat higher in patients with AVM obliteration (67\%) than in those with patent nidi (57\%), this difference was not statistically significant ( $\mathrm{p}=$ $0.404)$.

There is conflicting literature regarding the association of AVM obliteration with seizure control. ${ }^{6}$ The present study conflicts with prior studies, which reported superior rates of posttreatment seizure control in patients with obliterated AVMs compared with those with patent AVMs. Hoh et al. compared the seizure outcomes following multimodality treatment of 141 patients with seizures to 283 patients without seizures and found obliteration to be significantly associated with Engel Class I outcomes (p $<0.001){ }^{23} \mathrm{Lim}$ et al. reported a $77 \%$ rate of seizure control in $43 \mathrm{AVM}$ patients treated with radiosurgery. ${ }^{30}$ Patients with radiosurgery-induced AVM obliteration were significantly more likely to achieve seizure freedom $(\mathrm{p}<0.005)$. In a more recent radiosurgery AVM series of 86 patients with seizures at presentation, Yang et al. also found the rate of seizure freedom was significantly higher in patients with obliterated nidi compared with those with patent nidi (97\% vs $31 \%$, respectively; $p=0.001) .52$

In contrast, our findings are in agreement with those of Kurita et al., who studied 35 patients with unruptured, epileptogenic AVMs and did not find superior seizure control in patients with obliterated AVMs. ${ }^{29}$ Another AVM radiosurgery study of 15 pediatric patients with seizures at
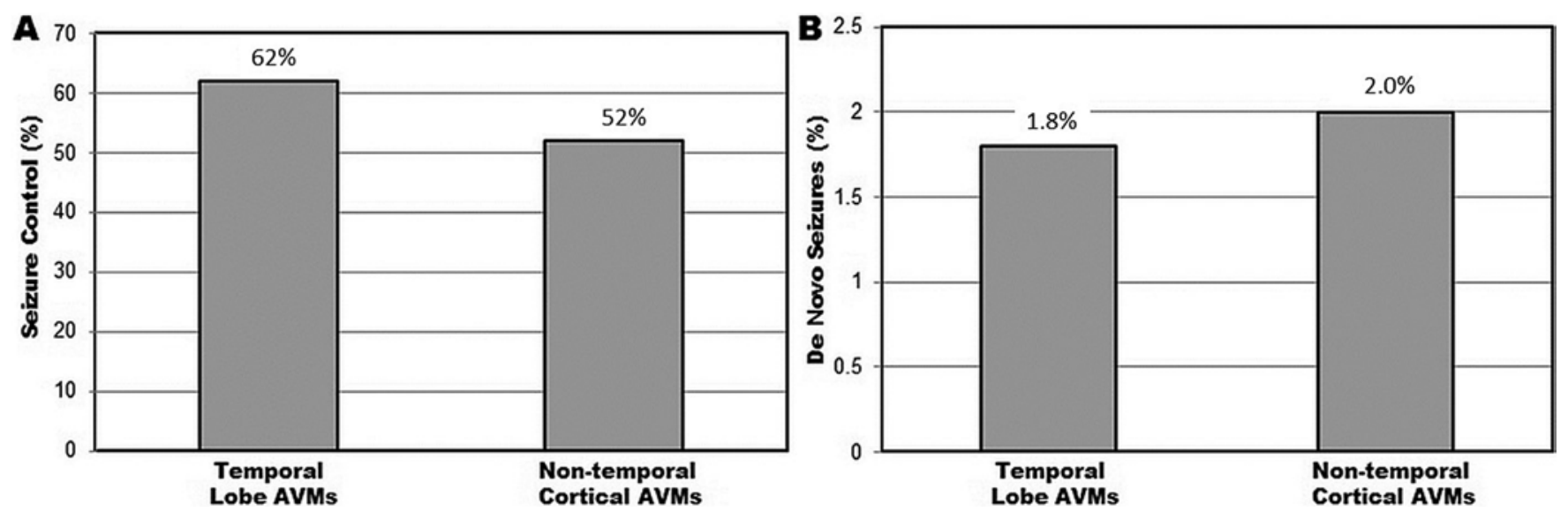

FIG. 2. A: Bar plot of seizure control rates for patients presenting with seizures in the temporal lobe AVM and non-temporal cortical AVM cohorts. There was no statistically significant difference in seizure control rates $(p=0.168)$. B: Bar plot of the incidences of de novo seizures in the temporal lobe AVM and non-temporal cortical AVM cohorts. There was no statistically significant difference in the incidences of de novo seizures $(p=0.925)$. 
TABLE 4. Univariate logistic regression analysis for predictors of seizure control in patients with seizure presentation*

\begin{tabular}{lcll}
\hline \multicolumn{1}{c}{ Factor } & OR & \multicolumn{1}{c}{$95 \% \mathrm{Cl}$} & $\mathrm{p} \mathrm{Value}$ \\
\hline Temporal lobe location & 1.510 & $0.819-2.784$ & 0.187 \\
\hline Male sex & 1.587 & $0.887-2.841$ & 0.120 \\
\hline Preradiosurgery hemorrhage & 4.309 & $0.917-20.238$ & 0.064 \\
\hline Preradiosurgery embolization & 2.081 & $1.108-3.909$ & $0.023 \dagger$ \\
\hline Higher volume & 1.091 & $0.998-1.192$ & 0.056 \\
\hline Non-eloquent location & 1.684 & $0.928-3.058$ & 0.087 \\
\hline Higher RBAS & 1.801 & $0.911-3.560$ & 0.091 \\
\hline Lower prescription dose & 1.107 & $1.012-1.212$ & $0.027 \dagger$ \\
\hline
\end{tabular}

* Covariates with $p<0.20$ are tabulated.

$\dagger$ Statistically significant $(p<0.05)$.

presentation did not find obliteration to be associated with seizure outcomes. ${ }^{22}$ Additionally, Schauble et al. reported on a series of 65 patients with AVM-associated seizures who underwent radiosurgery without a significant association between obliteration and seizure control. ${ }^{42}$ Engel Class I outcomes were observed in $78 \%$ of patients. Although there is an overall trend in the literature toward more favorable seizure outcomes in patients with AVM obliteration, the correlation between these 2 end points remains inconsistent.

Prior embolization $(\mathrm{p}=0.023)$ and lower prescription dose $(p=0.027)$ were predictors of seizure control in the univariate logistic regression analysis. While the deleterious effect of embolization on radiosurgery-induced AVM obliteration has been reported in numerous prior studies in association with multiple purported but largely unveri-

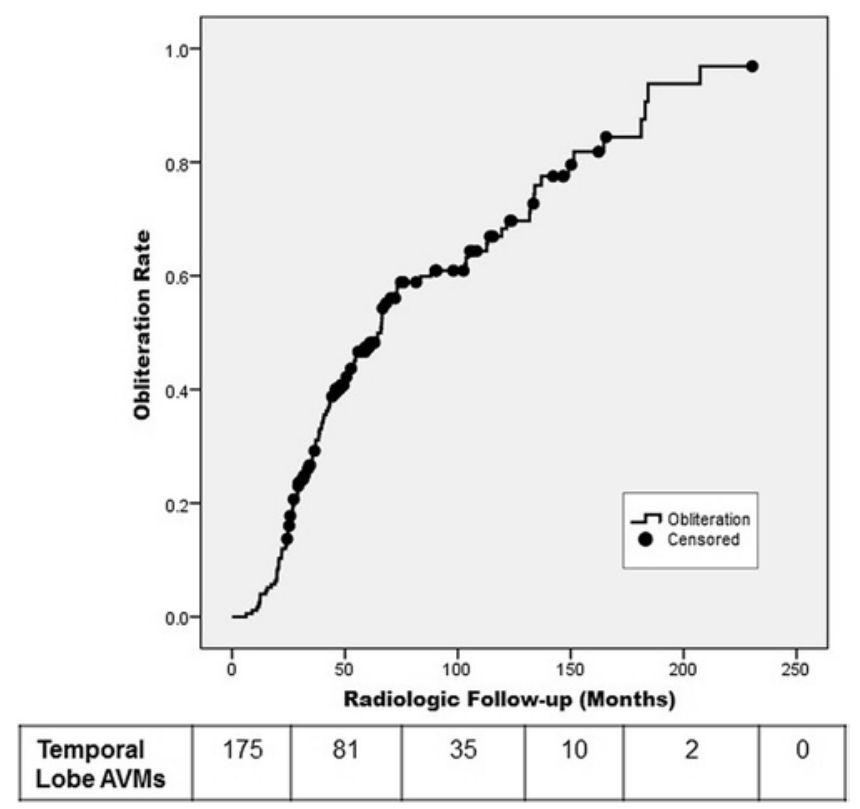

FIG. 3. Kaplan-Meier plot of the actuarial obliteration of temporal lobe AVMs over time. The obliteration rates at 3,5 , and 10 years were $29 \%$, $47 \%$, and $68 \%$, respectively. The number of patients remaining at each time point is shown under the $x$-axis. fied mechanisms, the effect of prior embolization on postradiosurgery seizure outcomes has not been previously described. . $, 4,26,37,44$ Our study suggests the novel finding that, for patients with AVM-associated epilepsy, prior embolization may have divergent effects on obliteration and seizure control. In a review of radiosurgery outcomes for mesial temporal lobe epilepsy (MTLE) yielding a total of 92 patients, Rolston et al. observed higher rates of seizure freedom in patients treated with a prescription dose of at least $24 \mathrm{~Gy}(58 \%)$ compared with those treated with less than 24 Gy (27\%). ${ }^{40}$ However, AVM-associated epilepsy may not share pathophysiological similarities with MTLE. ${ }^{39}$ Furthermore, while the anatomical features of temporal lobe AVMs may vary widely across patients, the anatomy of MTLE is relatively invariant. These distinctions between temporal lobe AVM-associated seizures and MTLE may account for the disparate associations between radiosurgical dose and seizure control. RIC may sensitize the perinidal cortex to excitatory stimuli and therefore predispose patients with postradiosurgery RIC to seizures. Although infrequent, RIC can cause de novo seizures, as observed in one patient in our series $(0.6 \%)$.

The most important finding of this case-control, retrospective evaluation of AVM-associated epilepsy was that temporal lobe location did not confer significantly different postradiosurgery seizure outcomes, regardless of a patient's initial presentation. Therefore, while temporal lobe AVM localization may predispose AVM patients to preradiosurgery epilepsy, it does not appear to dictate the like-

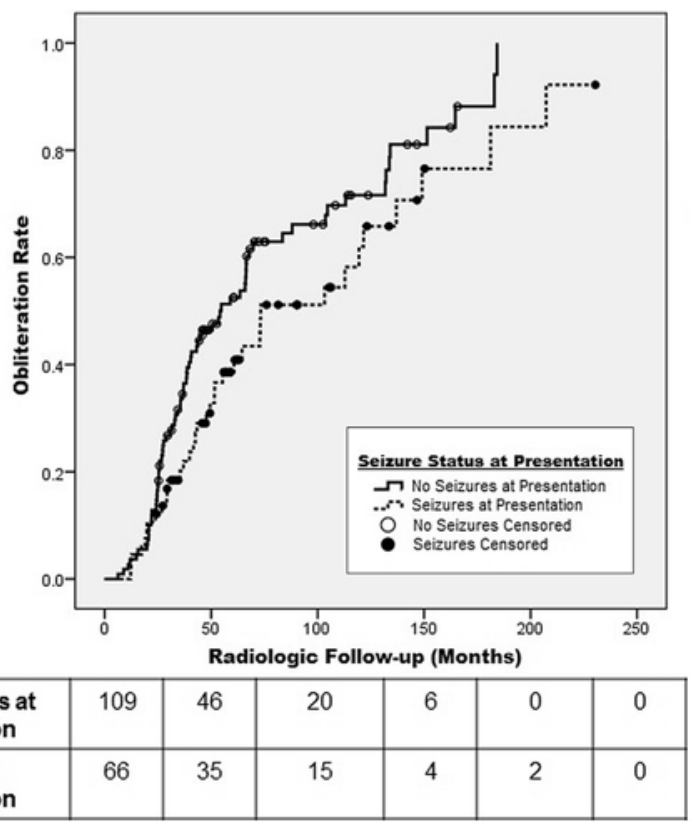

FIG. 4. Kaplan-Meier plots of the actuarial obliteration of temporal lobe AVMs based on seizure status at presentation. For patients with seizures at presentation, the obliteration rates at 3,5 , and 10 years were $20 \%, 39 \%$, and $62 \%$, respectively. For patients without seizures at presentation, the obliteration rates at 3,5 , and 10 years were $33 \%, 52 \%$, and $72 \%$, respectively. The actuarial obliteration rate was significantly higher in patients without presenting seizures ( $p=0.046$, log-rank test). The numbers of patients with and without presenting seizures remaining at each time point are shown under the $x$-axis. 
TABLE 5. Summary of the major temporal lobe AVM surgical series

\begin{tabular}{|c|c|c|c|c|c|c|c|c|}
\hline Authors and Year & $\begin{array}{l}\text { No. of } \\
\text { Patients }\end{array}$ & $\begin{array}{c}\text { Seizure at } \\
\text { Presentation (\%) }\end{array}$ & $\begin{array}{c}\text { Prior } \\
\text { Hemorrhage (\%) }\end{array}$ & $\begin{array}{l}\text { Obliteration } \\
\quad(\%)\end{array}$ & $\begin{array}{c}\text { Seizure } \\
\text { Control (\%) }\end{array}$ & $\begin{array}{c}\text { Permanent } \\
\text { Morbidity* }(\%)\end{array}$ & Mortality (\%) & $\begin{array}{c}\text { Favorable } \\
\text { Outcome† (\%) }\end{array}$ \\
\hline $\begin{array}{l}\text { Gabarrós Canals et } \\
\text { al., } 2013\end{array}$ & 88 & 27 & 51 & 93 & $N R$ & 17 & 5 & 87 \\
\hline $\begin{array}{l}\text { Lopez-Ojeda et al., } \\
\qquad 2013\end{array}$ & 29 & 41 & 52 & 93 & 75 & 10 & 0 & 86 \\
\hline Böstrom et al., 2011 & 44 & 45 & 34 & 98 & NR & 7 & 0 & NR \\
\hline Nagata et al., 2006 & 26 & 15 & 85 & 100 & 50 & 8 & 0 & NR \\
\hline Yamada et al., 1998 & 22 & 32 & 59 & 95 & 100 & 5 & 0 & 86 \\
\hline Malik et al., 1996 & 24 & 46 & 29 & NR & NR & 13 & 4 & NR \\
\hline
\end{tabular}

lihood of achieving radiosurgery-induced seizure control. Although the findings of this study refuted our hypothesis that temporal lobe location may portend poorer seizure outcomes, we nevertheless believe that this negative result is a relevant insight into AVM radiosurgery, given the particular predisposition of the temporal cortex toward epileptogenesis..$^{20,23,24,48}$ Therefore, temporal lobe location of an AVM and the concern for epilepsy should not serve as a deterrent for the use of radiosurgery in the management of patients harboring these lesions. Ultimately, the foremost goal of AVM treatment is obliteration, given the potentially catastrophic degree of neurological morbidity associated with AVM rupture. ${ }^{34}$ Persistence or worsening of pretreatment seizures, or development of de novo posttreatment seizures, may be managed by AED therapy and, in refractory cases, resection of the seizure focus based on cortical mapping and electroencephalography. Collaborative management of AVM-associated seizures with an epileptologist may optimize long-term outcomes and assuage patient-specific concerns.

\section{Study Limitations}

Despite the relatively large number of temporal lobe AVMs treated at our institution, the present study remains limited by its single center, retrospective nature, which subject it to the selection and treatment biases of the institution and the treating physicians. While clinical follow-up was obtained at the University of Virginia when feasible, many patients treated at our center reside in other states or countries, thereby rendering direct follow-up difficult. Due to the variable quality of clinical follow-up and the nature of being a tertiary referral center for radiosurgery, we were unable to stratify our seizure outcomes according to Engel classification, AED usage, and seizure subtype. Therefore, we were unable to determine the effect of seizure frequency or severity at presentation on postradiosurgery seizure outcomes. Additionally, obliteration was determined by MRI without angiographic confirmation in $18 \%$ of patients in this series. Although angiography is the gold standard for assessment of AVM obliteration, MRI has been shown to be an acceptably accurate substitute. Pollock et al. previously determined MRI to have $100 \%$ specificity, $80 \%$ sensitivity, and $91 \%$ negative predictive value com- pared with angiography. ${ }^{38}$ O'Connor and Friedman more recently reported an accuracy of $82 \%$ for MRI compared with angiography, which increased in 90\% for AVMs less than $2.8 \mathrm{~cm}^{3}$ in volume and, conversely, decreased to $70 \%$ for AVMs greater than $2.8 \mathrm{~cm}^{3}$ in volume. ${ }^{36}$

Our exclusion of patients with less than 2 years of radiological follow-up except those with AVM obliteration may bias our results toward more favorable outcomes. However, including all patients, even those with less than 2 years follow-up, would also bias our results albeit in an unfavorable manner. If only patients with at least 2 years of radiological follow-up were included $(n=153)$, rates of obliteration, cumulative RIC, symptomatic RIC, permanent RIC, and annual postradiosurgery hemorrhage risk were $58 \%$, $31 \%, 2 \%, 0.7 \%$, and $1.2 \%$, respectively. The rates of seizure control and worsened seizure outcomes were 62\% (36/58 patients) and $9 \%$ (5/58 patients), respectively. The incidence of de novo seizures in patients without presenting seizures was $2.1 \%$ (2/95 patients). Hence, broadening or restricting the inclusion criteria would not have significantly altered the reported postradiosurgery outcomes. Finally, we acknowledge that an analysis of the seizure outcomes for all AVMs treated with radiosurgery is lacking in the current study. However, we believe that, given the aims of this study, the aforementioned analysis may detract from the main conclusions and is therefore outside of the scope of the current work.

\section{Conclusions}

We present the first analysis of radiosurgery outcomes for temporal lobe AVMs. Radiosurgery affords a reasonable obliteration rate for temporal lobe AVMs with relatively low rates of symptomatic RIC and latency period hemorrhage. Additionally, radiosurgery effectively reduces seizure frequency for patients with temporal lobe AVM-associated seizures. A minority of patients will develop new or worsening seizures following radiosurgery. A comparison of temporal lobe AVMs to angioarchitecturally similar non-temporal, cortical AVMs determined that temporal lobe location did not affect postradiosurgery seizure outcomes. Thus, temporal lobe AVM location and a concern for epilepsy should not be seen as a deterrent for treatment 
with radiosurgery. Furthermore, the routine use of prophylactic anticonvulsants in patients with temporal lobe or extratemporal, cortical AVMs undergoing radiosurgery does not appear warranted.

\section{References}

1. Andrade-Souza YM, Ramani M, Scora D, Tsao MN, terBrugge K, Schwartz ML: Embolization before radiosurgery reduces the obliteration rate of arteriovenous malformations. Neurosurgery 60:443-452, 2007

2. Baranoski JF, Grant RA, Hirsch LJ, Visintainer P, Gerrard JL, Gunel M, et al: Seizure control for intracranial arteriovenous malformations is directly related to treatment modality: a meta-analysis. J Neurointerv Surg 6:684-690, 2014

3. Boström A, Schaller K, Seifert J, Schramm J: The place for surgical treatment for AVM involving the temporal lobe. Acta Neurochir (Wien) 153:271-278, 2011

4. Buell TJ, Ding D, Starke RM, Webster Crowley R, Liu KC: Embolization-induced angiogenesis in cerebral arteriovenous malformations. J Clin Neurosci 21:1866-1871, 2014

5. Chang SD, Shuster DL, Steinberg GK, Levy RP, Frankel K: Stereotactic radiosurgery of arteriovenous malformations: pathologic changes in resected tissue. Clin Neuropathol 16:111-116, 1997

6. Chen CJ, Chivukula S, Ding D, Starke RM, Lee CC, Yen CP, et al: Seizure outcomes following radiosurgery for cerebral arteriovenous malformations. Neurosurg Focus 37(3):E17, 2014

7. Cogan GB, Thesen T, Carlson C, Doyle W, Devinsky O, Pesaran B: Sensory-motor transformations for speech occur bilaterally. Nature 507:94-98, 2014

8. Ding D, Yen CP, Starke RM, Xu Z, Sheehan JP: Radiosurgery for ruptured intracranial arteriovenous malformations. J Neurosurg 121:470-481, 2014

9. Ding D, Yen CP, Starke RM, Xu Z, Sun X, Sheehan JP: Outcomes following single-session radiosurgery for high-grade intracranial arteriovenous malformations. Br J Neurosurg 28:666-674, 2014

10. Ding D, Yen CP, Starke RM, Xu Z, Sun X, Sheehan JP: Radiosurgery for Spetzler-Martin Grade III arteriovenous malformations. J Neurosurg 120:959-969, 2014

11. Ding D, Yen CP, Xu Z, Starke RM, Sheehan JP: Radiosurgery for low-grade intracranial arteriovenous malformations. J Neurosurg 121:457-467, 2014

12. Ding D, Yen CP, Xu Z, Starke RM, Sheehan JP: Radiosurgery for patients with unruptured intracranial arteriovenous malformations. J Neurosurg 118:958-966, 2013

13. Ding D, Yen CP, Xu Z, Starke RM, Sheehan JP: Radiosurgery for primary motor and sensory cortex arteriovenous malformations: outcomes and the effect of eloquent location. Neurosurgery 73:816-824, 824, 2013

14. Engel J Jr, McDermott MP, Wiebe S, Langfitt JT, Stern JM, Dewar S, et al: Early surgical therapy for drug-resistant temporal lobe epilepsy: a randomized trial. JAMA 307:922-930, 2012

15. Fernandez-Miranda JC, de Oliveira E, Rubino PA, Wen HT, Rhoton AL Jr: Microvascular anatomy of the medial temporal region: part 1: its application to arteriovenous malformation surgery. Neurosurgery 67 (3 Suppl Operative):ons237ons 276,2010

16. Fierstra J, Conklin J, Krings T, Slessarev M, Han JS, Fisher JA, et al: Impaired peri-nidal cerebrovascular reserve in seizure patients with brain arteriovenous malformations. Brain 134:100-109, 2011

17. Forcelli PA, Palchik G, Leath T, DesJardin JT, Gale K, Malkova L: Memory loss in a nonnavigational spatial task after hippocampal inactivation in monkeys. Proc Natl Acad Sci U S A 111:4315-4320, 2014
18. Gabarrós A, Young WL, McDermott MW, Lawton MT: Language and motor mapping during resection of brain arteriovenous malformations: indications, feasibility, and utility. Neurosurgery 68:744-752, 2011

19. Gabarrós Canals A, Rodríguez-Hernández A, Young WL, Lawton MT: Temporal lobe arteriovenous malformations: anatomical subtypes, surgical strategy, and outcomes. J Neurosurg 119:616-628, 2013

20. Galletti F, Costa C, Cupini LM, Eusebi P, Hamam M, Caputo $\mathrm{N}$, et al: Brain arteriovenous malformations and seizures: an Italian study. J Neurol Neurosurg Psychiatry 85:284-288, 2014

21. Garcin B, Houdart E, Porcher R, Manchon E, Saint-Maurice JP, Bresson D, et al: Epileptic seizures at initial presentation in patients with brain arteriovenous malformation. Neurology 78:626-631, 2012

22. Gerszten PC, Adelson PD, Kondziolka D, Flickinger JC, Lunsford LD: Seizure outcome in children treated for arteriovenous malformations using gamma knife radiosurgery. Pediatr Neurosurg 24:139-144, 1996

23. Hoh BL, Chapman PH, Loeffler JS, Carter BS, Ogilvy CS: Results of multimodality treatment for 141 patients with brain arteriovenous malformations and seizures: factors associated with seizure incidence and seizure outcomes. Neurosurgery 51:303-311, 2002

24. Hyun SJ, Kong DS, Lee JI, Kim JS, Hong SC: Cerebral arteriovenous malformations and seizures: differential impact on the time to seizure-free state according to the treatment modalities. Acta Neurochir (Wien) 154:1003-1010, 2012

25. Jones JE, Berven NL, Ramirez L, Woodard A, Hermann BP: Long-term psychosocial outcomes of anterior temporal lobectomy. Epilepsia 43:896-903, 2002

26. Kano H, Kondziolka D, Flickinger JC, Park KJ, Iyer A, Yang $\mathrm{HC}$, et al: Stereotactic radiosurgery for arteriovenous malformations after embolization: a case-control study. J Neurosurg 117:265-275, 2012

27. Kano H, Lunsford LD, Flickinger JC, Yang HC, Flannery TJ, Awan NR, et al: Stereotactic radiosurgery for arteriovenous malformations, Part 1: management of Spetzler-Martin Grade I and II arteriovenous malformations. J Neurosurg 116:11-20, 2012

28. Kraemer DL, Awad IA: Vascular malformations and epilepsy: clinical considerations and basic mechanisms. Epilepsia 35 (Suppl 6):S30-S43, 1994

29. Kurita H, Kawamoto S, Suzuki I, Sasaki T, Tago M, Terahara A, et al: Control of epilepsy associated with cerebral arteriovenous malformations after radiosurgery. J Neurol Neurosurg Psychiatry 65:648-655, 1998

30. Lim YJ, Lee CY, Koh JS, Kim TS, Kim GK, Rhee BA: Seizure control of Gamma Knife radiosurgery for non-hemorrhagic arteriovenous malformations. Acta Neurochir Suppl 99:97-101, 2006

31. Lopez-Ojeda P, Labib M, Burneo J, Lownie SP: Temporal lobe arteriovenous malformations: surgical outcomes with a focus on visual field defects and epilepsy. Neurosurgery 73:854-862, 2013

32. Malik GM, Seyfried DM, Morgan JK: Temporal lobe arteriovenous malformations: surgical management and outcome. Surg Neurol 46:106-115, 1996

33. Maruyama K, Kawahara N, Shin M, Tago M, Kishimoto J, Kurita H, et al: The risk of hemorrhage after radiosurgery for cerebral arteriovenous malformations. N Engl J Med 352:146-153, 2005

34. Morgenstern LB, Hemphill JC III, Anderson C, Becker K, Broderick JP, Connolly ES Jr, et al: Guidelines for the management of spontaneous intracerebral hemorrhage: a guideline for healthcare professionals from the American Heart Association/American Stroke Association. Stroke 41:21082129,2010 
35. Nagata S, Morioka T, Matsukado K, Natori Y, Sasaki T: Retrospective analysis of the surgically treated temporal lobe arteriovenous malformations with focus on the visual field defects and epilepsy. Surg Neurol 66:50-55, 2006

36. O'Connor TE, Friedman WA: Magnetic resonance imaging assessment of cerebral arteriovenous malformation obliteration after stereotactic radiosurgery. Neurosurgery 73:761766, 2013

37. Pollock BE, Flickinger JC, Lunsford LD, Maitz A, Kondziolka D: Factors associated with successful arteriovenous malformation radiosurgery. Neurosurgery 42:1239-1247, 1998

38. Pollock BE, Kondziolka D, Flickinger JC, Patel AK, Bissonette DJ, Lunsford LD: Magnetic resonance imaging: an accurate method to evaluate arteriovenous malformations after stereotactic radiosurgery. J Neurosurg 85:1044-1049, 1996

39. Quigg M, Rolston J, Barbaro NM: Radiosurgery for epilepsy: clinical experience and potential antiepileptic mechanisms. Epilepsia 53:7-15, 2012

40. Rolston JD, Quigg M, Barbaro NM: Gamma knife radiosurgery for mesial temporal lobe epilepsy. Epilepsy Res Treat 2011:840616, 2011

41. Schaller C, Schramm J, Haun D: Significance of factors contributing to surgical complications and to late outcome after elective surgery of cerebral arteriovenous malformations. J Neurol Neurosurg Psychiatry 65:547-554, 1998

42. Schäuble B, Cascino GD, Pollock BE, Gorman DA, Weigand S, Cohen-Gadol AA, et al: Seizure outcomes after stereotactic radiosurgery for cerebral arteriovenous malformations. Neurology 63:683-687, 2004

43. Schneider BF, Eberhard DA, Steiner LE: Histopathology of arteriovenous malformations after gamma knife radiosurgery. J Neurosurg 87:352-357, 1997

44. Schwyzer L, Yen CP, Evans A, Zavoian S, Steiner L: Longterm results of gamma knife surgery for partially embolized arteriovenous malformations. Neurosurgery 71:1139-1148, 2012

45. Spetzler RF, Martin NA: A proposed grading system for arteriovenous malformations. J Neurosurg 65:476-483, 1986

46. Starke RM, Yen CP, Ding D, Sheehan JP: A practical grading scale for predicting outcome after radiosurgery for arteriovenous malformations: analysis of 1012 treated patients. J Neurosurg 119:981-987, 2013
47. Steiner L, Lindquist C, Adler JR, Torner JC, Alves W, Steiner $\mathrm{M}$ : Clinical outcome of radiosurgery for cerebral arteriovenous malformations. J Neurosurg 77:1-8, 1992

48. Turjman F, Massoud TF, Sayre JW, Viñuela F, Guglielmi G, Duckwiler G: Epilepsy associated with cerebral arteriovenous malformations: a multivariate analysis of angioarchitectural characteristics. AJNR Am J Neuroradiol 16:345-350, 1995

49. Wegner RE, Oysul K, Pollock BE, Sirin S, Kondziolka D, Niranjan A, et al: A modified radiosurgery-based arteriovenous malformation grading scale and its correlation with outcomes. Int J Radiat Oncol Biol Phys 79:1147-1150, 2011

50. Wiebe S, Blume WT, Girvin JP, Eliasziw M: A randomized, controlled trial of surgery for temporal-lobe epilepsy. $\mathbf{N ~ E n g l ~}$ J Med 345:311-318, 2001

51. Yamada S, Brauer F, Dayes L, Yamada S: Surgical techniques for arteriovenous malformations in functional areas: focus on the superior temporal gyrus. Neurol Med Chir (Tokyo) 38 (Suppl):222-226, 1998

52. Yang SY, Kim DG, Chung HT, Paek SH: Radiosurgery for unruptured cerebral arteriovenous malformations: long-term seizure outcome. Neurology 78:1292-1298, 2012

53. Yeh HS, Privitera MD: Secondary epileptogenesis in cerebral arteriovenous malformations. Arch Neurol 48:1122-1124, 1991

\section{Author Contributions}

Conception and design: Sheehan, Ding, Quigg. Acquisition of data: Ding, Yen, Przybylowski, Dodson. Analysis and interpretation of data: Sheehan, Ding, Quigg, Starke, Xu, Yen. Drafting the article: Sheehan, Ding, Quigg. Critically revising the article: all authors. Reviewed submitted version of manuscript: all authors. Approved the final version of the manuscript on behalf of all authors: Sheehan. Statistical analysis: Ding, Starke, Xu.

\section{Correspondence}

Jason Sheehan, Department of Neurosurgery, University of Virginia, P.O. Box 800212, Charlottesville, VA 22908. email: jsheehan@virginia.edu. 